\title{
Strategic Leadership to Prevent Corruption in Indonesia
}

\author{
Fitria Rahmawati AR \\ Indonesian Defense University, \\ Bogor 16810, Indonesia \\ Aris Sarjito \\ Indonesian Defense University, \\ Bogor 16810, Indonesia
}

\begin{abstract}
In the General Explanation of the 2002 KPK Law, it states: Increased corruption unhindered creates disasters, not only for the national economy, but also for national and state life in general. Extensive and systematic corruption is also a violation of the social and economic rights of the community and, therefore, corruption can no longer be classified as an ordinary crime, but rather as an extraordinary crime. By any standard, Indonesia's corruption level is high. There are indications that since the fall of Suharto, overall corruption has actually increased. Regional autonomy is generally blamed for dispersing power to regional officials, many of whom are expected to exploit their offices for personal gain. This study uses a qualitative analysis approach that aims to analyze strategic leadership to prevent corruption in Indonesia, using Hughes's strategic leadership theory as an analysis tool. The results of this study are: (1) good governance requires transparency in the management of regional development using the budget originating from the APBN (state budget) and APBD (local budget); (2) strategic leaders always encourage the creation of clean bureaucracy; Organizational principles are encouraged to prohibit illegal actions against the internal environment and, in particular, external organizations will have an impact in the long term and grow the organization to be healthier; and (3) a strategic leader in running an organization must hold fast to the principle of legality and anticorruption.
\end{abstract}

Keywords: corruption, strategic leadership.

\section{INTRODUCTION}

Corruption, operationally defined by Transparency International (TI), "as an abuse of entrusted power for personal gain." The problem of corruption is not new, perhaps as old as the state as a political organization with the prerogative to allocate resources. Investigation of corruption activities occurs in public administration in some parts of the world, which causes poverty, child mortality, hunger, illiteracy, and so on. Corruption cannot be eradicated and continues to absorb resources from many of the world's poorest countries.

Corruption is considered to be progressively weakening the institutional foundations where economic growth and social justice depend, often leading to institutional inefficiencies and, in turn, priority distortions and development outcomes. The World Bank has prioritized corruption eradication policies for the development community. Extensive reform efforts have been made in the past two decades. This reform was built on the understanding that corruption is a public administration dysfunction contained in monopolies and policies, which can then be overcome by encouraging accountability and transparency. Corruption devastated programs and policies aimed at reducing poverty. So, fighting corruption is very important to achieving the overall mission of the World Bank on poverty alleviation. 
Borrowing the words of former World Bank President James Wolfensohn "'Cancer corruption' is incompatible with development." Or as when former UN Secretary General Kofi Annan commented; "Good governance may be the single most important factor in eradicating poverty and promoting development." Also, as recognized by the World Bank; "In many countries, donors underestimate the importance of governance and institutional reform. As a result, weaknesses in governance and institutions hamper productivity growth and eradicate poverty resulting from macroeconomic reforms." And a 2005 joint report by the International Monetary Fund and the World Bank said, "A broad consensus has emerged that development assistance is very effective in this country - poor countries with good economic policies and institutional environments."

Therefore, the crime of corruption is an extraordinary crime. Corruption is often carried out in a planned and systematic manner and is a violation of the social and economic rights of the community at large and endemic, damaging the joints of the national economy, and degrading the nation's dignity in international forums, so that the eradication must be done extraordinarily because of the action against perpetrators corruption must be specifically regulated.

Transparency International - the world body observing efforts to eradicate corruption by the government, business world and civil society released the Annual Report on Corruption Perception Index in 2018. The survey results of 180 countries showed a sad picture because more than two-thirds scored less than 50 . Highest score is 100 , which means it is very clean or corruption free, and the lowest is zero which means it is very corrupt.

Only 20 countries have shown significant progress in efforts to eradicate corruption in recent years, namely Denmark, New Zealand, Finland, Singapore, Sweden, Switzerland, Norway, the Netherlands, Canada, Luxembourg, Germany, England, Australia, Austria, Hong Kong, Iceland, Belgium, Estonia, Ireland and Japan.

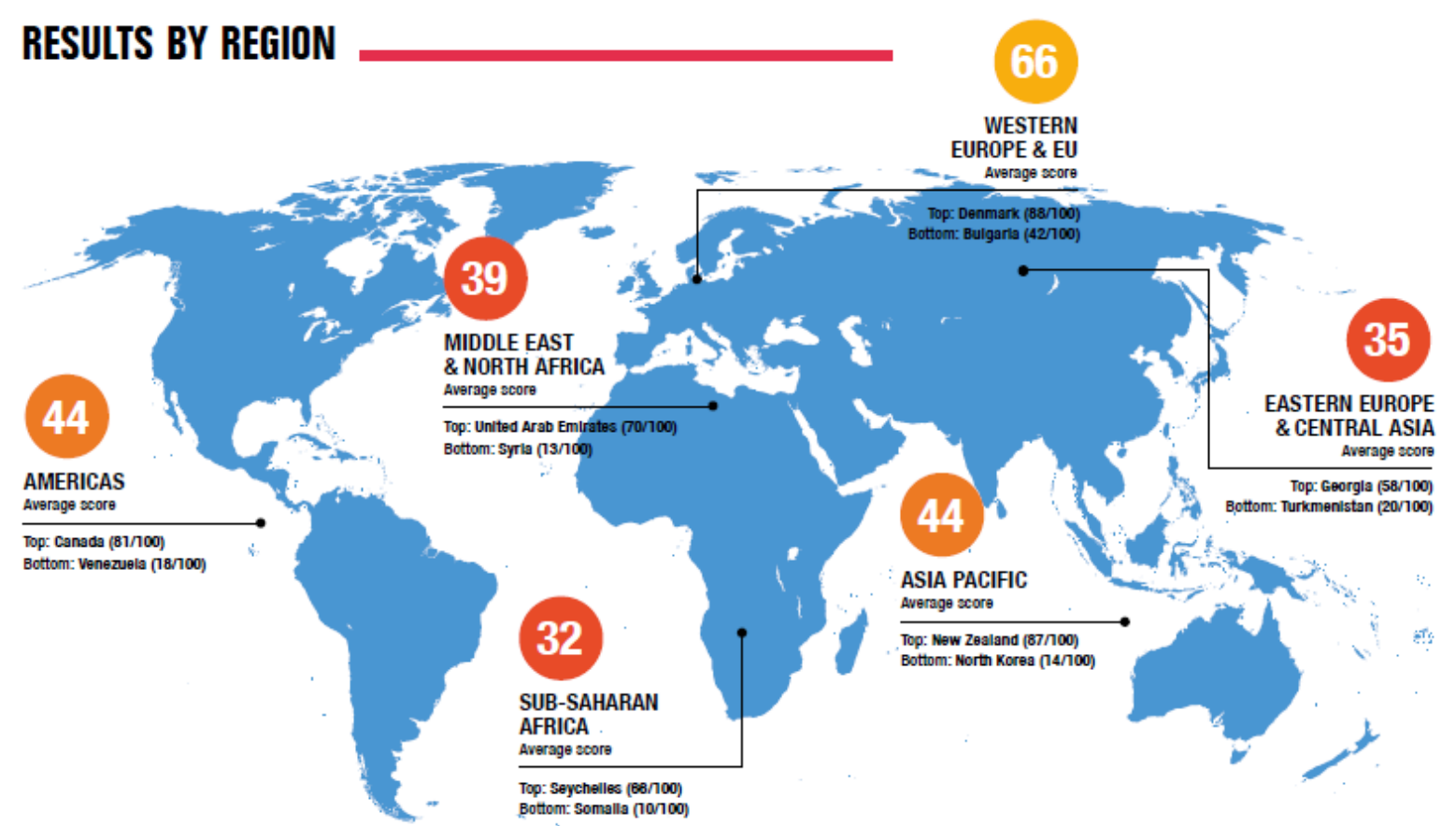

The 2018 Corruption Perceptions Index, published by Transparency International, measures the perceived levels of public sector corruption in 180 countries and territories. 
In Indonesia, post-Soeharto is at a critical point. Many of the decisive characteristics of the 32 years of Suharto's authoritarian rule were removed. Indonesia has changed from one of the most repressive and centralized political systems in Southeast Asia to the most decentralized and democratically electoral system. However, more than a decade after the fall of Suharto in May 1998, the reformers could not let go of one of their eternal inheritances, namely corruption. Indonesia is often said to have a level of corruption among the highest in the world. In the Transparency International Corruption Perceptions Index, Indonesia placed 110 out of 170 countries in 2010. Corruption is said to be rooted in all levels of government - national, provincial, city and village. Many of its institutions, including the parliament and national courts, are among the most corrupt in Asia (Diansyah 2009). All this leads Emmerson (2010) to describe Indonesia as the most democratic and most corrupt country in the region.

The link between leadership and corruption is generally difficult to meet, because both of them do not show in one problem that can be equalized. However, if tried, it is associated with the understanding that leadership can only give birth, or allow the occurrence of acts of corruption. It is relevant that these two terms are positioned as two issues that can support each other and even fulfil each other.

Strategic leadership focuses on achieving sustainable competitive advantage and broad reach to advance the organization. By implementing strategic leadership, it is expected to reduce the growth of corruption in Indonesia.

\section{Corruption}

\section{LITERATURE REVIEW}

Corruption is a moral category that signifies putrefaction and rot. Corruption is also a legal category. All states have laws against bribery and fraud in the public sector and most regulate campaign contributions, campaign spending and conflicts of interest (Ackerman, 2006).

The narrow definition of corruption adequately describes the diverse ways in which public power is abused for private gain. A broader formulation of corruption refers more generally to the vulnerability of states to market forces, to the power of capital, to the influence of wealthy voters and interest groups (Sullivan, 2002: 100).

Corruption according to Heidenheimer (2002) is classified into the following three categories: (1) Black corruption, that is, certain actions which constitute a majority consensus from the elite and condemn public opinion and want to see the punishment carried out based on legal principles; (2) Grey corruption, that is, some elements (usually elites), who might want to see the act of corruption being punished while others do not, and the majority may be ambiguous; and (3) White corruption, that is, most elite opinion and the masses do not enthusiastically support efforts to punish the forms of corruption that they consider tolerable.

In bureaucracy, it is prone to corruption because it can involve legal and illegal activities. Bureaucracy is a feature of most large organizations and especially applies to government. Bureaucracy in Third World countries has the worst reputation (Robb, 2002: 49).

Corruption analysis is recommended for the following reasons: at present, there is no methodology or index to measure the level of corruption in various sectors of activity. Civil society and various international bodies have negative perceptions about a range of activity sectors, such as: justice, administration, public health, public education, public administration, but there are no standards to measure the size of corruption in this field (Andrei, 2009: 16). 


\section{Leadership}

A study and analysis of the popular definitions on leadership reveals that most definitions tend to focus on the individual traits and characteristics. Prominent figures have their own views and therefore have clear leadership. Some definitions of leadership are as follows:

Leadership is an influence process that enable managers to get their people to do willingly what must be done, do well what ought to be done. (Cribbin, 1981).

Leadership is the art of influencing others to their maximum performance to accomplish any task, objective or project. (Cohen, 1990: 9).

Leadership is that process in which one person sets the purpose or direction for one or more other persons and gets them to move along together with him or her and with each other in that direction with competence and full commitment. (Jaques E. \& Clement, 1994).

Some definitions of leadership reveal that the main context is personality. There seems to be a certain independence regarding contemporary issues. Nonetheless, leadership is not just about getting things done or getting other people to do what is wanted to be done. To lead is also to motivate and inspire others. In the other words, leadership is the ability to get someone else to do, delegation, what you want done, direction, because they want to do it, motivation. (Fragueiro, 2011: 121).

\section{Strategic Leadership}

All strategic leadership starts with the chief executive, and in order to succeed, he or she must understand the playing field. Once the strategy is set, success relies on the issue resolution systems that will implement the strategy. A chief executive must fully understand each area and how it will affect and be affected by strategy (Freedman, 2003).

The study of executive leadership from a strategic choice perspective, or more concisely, strategic leadership, focuses on the executives who have overall responsibility for an organization, their characteristics, what they do, how they do it, and particularly, how they affect organizational outcomes (Cannella, 2009).

People in strategic leadership positions need to be aware of this sea of messages, be able to decipher them, and follow up with wise wisdom. These wide-range signals and messages, often in contexts not seen in board meetings, top management teams, and task forces, flow through the organization through a wide network of relationships between leaders and followers, laterally between colleagues and hierarchically between leaders and subordinates (Kriger, 2016: 4).

The focus of strategic leadership is sustainable competitive advantage, or the enduring success of the organization. Hughes (2005: 11) stated that strategic leadership is exerted when the decisions and actions of leaders have strategic implications for the organization. It might also be described in this way: (1) Strategic leadership is broad in scope. This broad scope requires seeing the organization as an interdependent and interconnected system of multiple parts, where decisions in one area provoke actions in other areas; (2) The impact of strategic leadership is felt over long periods of time. The strategic leader must keep long-term goals in mind while working to achieve short-term objectives; and (3) strategic leadership often involves significant organizational change. A third way strategic leadership differs from leadership in general is that it results in significant change. 


\section{METHODOLOGY}

This paper uses a descriptive qualitative approach model as the primary writing approach. The data used in this writing is secondary data, where secondary data is generally in the form of evidence, records, or historical reports that have been compiled in archives (documentary data), both published and unpublished (Moleong, 2014).

The techniques used to collect data in this paper are: (1) Study of literature, a series of activities related to the method of collecting literature, reading, recording, and processing research materials; (2) Documentaries, documentation studies conducted by reading previous writing reports and journals relating to this writing. In this method, the author simply moves the relevant data from the source or document needed; (3) Discussion, collecting data by discussing ideas with people who are competent in this matter to solve certain problems related to this paper; (4) Intuitive-Subjective, is the involvement of the author's opinion about the problem being discussed (Ghofar, 1999).

\section{DISCUSSION}

Strategic leadership is a process that provides the direction and inspiration needed to create and implement an organization's vision, mission, and strategy to achieve organizational goals. Strategic leadership must involve managers at the top, middle and lower levels of the organization. Strategic leaders make decisions and actions that have strategic implications for the organization, namely: (1) strategic leadership has a wide range; (2) the impact of strategic leadership is felt in the long term; and (3) strategic leadership often involves significant organizational change.

\section{Strategic leadership has a wide range}

The broad scope of strategic leadership means having a broad impact beyond the area of functional units and business leaders, and even outside the organization. With this broad scope requires organizations to see as interdependent and interconnected systems from many parts, where decisions in one field will trigger action in another.

The analogy is like waves in the ocean. Each wave that hits a surface will move in response to a broken wave. External forces, such as wind, also affect wave levels. Likewise, with leadership. The broad scope of strategic leadership is beyond the organization, acting and reacting to trends and problems in the environment.

Strategic leadership with wide coverage for local government organizations is so important to always be discouraged given the large number of public leaders, especially the Regional Head, who are involved in cases of violations of public ethics in leading and managing their regions. The dominant violation of public ethics by public leaders is corruption. Good governance requires transparency in the management of regional development using the budget originating from the APBN (state budget) and APBD (local budget). Strategic leaders always encourage the creation of:

Clean bureaucracy, includes: (1) high integrity, high durability, and anti-corruption; (2) free from abuse of authority; and (3) collaborative, democratic and participatory leadership. While competent bureaucracy, includes: (1) professional, competent needed, expert, and skilled; (2) understanding, understanding and broad-minded; and (3) continue learning, knowledge manager for organizations.

Bureaucracy that serves: (1) nice to serve and empathize high; (2) work together and have a wide network; (3) customer / community oriented; (4) prioritize the public interest; and (5) courteous, careful, serving with heart and heart. 
Strategic leaders carry out organizational structuring by considering trends in long-term changes of external factors that have the potential to have significant influence. Organizational structuring is carried out by establishing an organizational structure that is appropriate to the needs and functions, does not occur in contradiction, is not redundant and is not fragmented or less integrated. Important organizational goals can be achieved as believed by the Weberians (adherents of Max Weber) with classical thinking, namely the existence of: good division of tasks, adequate division of authority and separation of functions, pay attention to the span of control from management, and pay attention to the unity of command (unity of command).

\section{The impact of strategic leadership is left for a long time}

Like its scope, the strategic leadership time frame is also far reaching. Strategic leaders must remember long-term goals while working to achieve short-term goals. Nearly half a millennium ago, Japanese military leader Miyamoto Musashi said, "In strategy, it is important to see things that are far away as if they are close and to take a long-distance view of things that are close" (Advice on Strategy, n.d).

His precise observations illustrate the tension between short and long-term perspectives that strategic leaders must balance. Strategic leadership is crucial for the government because it will bring organizations to a better direction and can develop their potential. Organizational principles are encouraged to prohibit illegal actions against the internal environment and, in particular, external organizations will have an impact in the long term and grow the organization to be healthier.

Furthermore, Cobbold, et al., (2004) concluded that the crucial role of strategic leadership is in creating goals, values, and systems that lead to continuous performance improvement. To be able to be a good leader a manager must be able to develop himself continuously, and be able to influence, inspire, and direct employees properly to be able to achieve organizational goals. Variables Strategic leadership is formed by 4 indicators, namely promotion orientation, providing guidance, being on time and prioritizing collaboration (Lumpkin and Dess, 1996). The value system developed by strategic leaders is guided by the principle of legality and anticorruption.

\section{Strategic leadership often involves significant organizational change}

The difference between strategic leadership and leadership in general is that strategic leadership produces significant changes. The main purpose of organizational change is to improve organizational functions. Increasing productivity and organizational effectiveness has implications for the ability of organizations to make quality decisions by making changes to structure, culture, duties, technology, and human resources. The main approach is to develop an organizational culture that can maximize people's involvement in making effective decisions in organizations.

Factors of change can occur due to internal factors and external factors. Internal factors are all the overall factors in the organization where these factors can affect the organization and activities of the organization. Problems that often arise are related to fellow member relationships which generally involve communication problems and the interests of each member. The process of cooperation that takes place is also sometimes the cause of change. Rigid bureaucratic systems cause relationships between members to be impersonal which results in low morale and in turn productivity decreases.

Problems that often arise in organizations are: problems of relationships between members, problems in the process of employment relations, financial problems, changes in 
environmental policy, changes in organizational goals, expansion of the operational area of the organization's objectives, increasing volume of activities, and attitudes and behaviour of organizational members

External factors are all overall factors that exist outside the organization that affect the organization. Some of these external factors include: politics, law, culture, technology, natural resources, demographics, and so on. These external factors become very important when organizations face political and legal uncertainty. A strategic leader in running an organization must hold fast to the principles of legality and anti-corruption.

\section{CONCLUSION}

Indonesia has changed from one of the most repressive and centralized political systems in Southeast Asia to the most decentralized and democratic system. Even so, there are still obstacles that prevent Indonesia from achieving the 'rule of law', and in particular, this country consistently ranks as one of the countries with the highest corruption in the world.

Corruption behaviour by bureaucrats, one of the contributing factors is weak leadership in government organizations. Strategic leadership can be one solution to prevent corruption in Indonesia.

Strategic leadership with wide coverage for local government organizations is so important to always be discouraged given the large number of public leaders, especially the Regional Head, who are involved in cases of violations of public ethics in leading and managing their regions. The dominant violation of public ethics by public leaders is corruption. Good governance requires transparency in the management of regional development using the budget originating from the APBN (state budget) and APBD (local budget). Strategic leaders always encourage creation: clean bureaucracy, competent bureaucracy, and service bureaucracy.

Strategic leaders must remember long-term goals while working to achieve short-term goals. Organizational principles are encouraged to prohibit illegal actions against the internal environment and, in particular, external organizations will have an impact in the long term and grow the organization to be healthier.

Strategic leadership must produce significant changes. Factors of change can occur due to internal factors and external factors. These external factors become very important when organizations face political and legal uncertainty. A strategic leader in running an organization must hold fast to the principle of legality and anti-corruption.

\section{References}

Ackerman, Susan Rose. International Handbook on the Economics of Corruption, Edward Elgar Publishing, Inc., Northampton, Massachusetts, USA, 2006.

Andrei, Tudorel. The Corruption: An Economic and Social Analysis, Editura Economică, București, 2009.

Cohen, W.A. The Art of a Leader, Englewood Cliffs, Prentice Hall, New York, 1990.

Cribbin, James J. Strategies for Organizational Effectiveness, Amacom, New York., 1981.

Finkelstein, Sydney et al. Strategic Leadership: Theory and Research on Executives, Top Management Teams, and Boards, Oxford University Press, Inc., New York, 2009.

Fragueiro, Fernando and Thomas, Howard. Strategic Leadership in the Business School: Keeping One Step Ahead, Cambridge University Press, Cambridge, UK, 2011.

Freedman, Mike. The Art and Discipline of Strategic Leadership, Mcgraw-Hill, New York, 2003. 
Rahmawati, F. AR., \& Sarjito, A. (2020). Strategic Leadership to Prevent Corruption in Indonesia. Advances in Social Sciences Research Journal, 7(1) 158-165.

Heidenheimer, Arnold J. and Jacob van Klaveren Michael Johnston. Political Corruption: concepts and contexts, Transaction Publishers, New Brunswick, New Jersey, 2002.

Hughes, Richard L. and Beatty, Colarelli, Katherine. Becoming a Strategic Leader -Your Role in Your Organization's, Jossey-Bass A Wiley Imprint, San Francisco, 2005.

Jaques, E., \& Clement, S. D. Executive leadership: A practical guide to managing complexity. Malden, Mass, Blackwell, 1994.

Kriger, Mark and Zhovtobryukh, Yuriy. Strategic Leadership for Turbulent Times, Palgrave Macmillan, US, 2016.

Robb, Stuart Poole and Bailey, Alan. Risky Business: Corruption, Fraud, Terrorism and other Threats to Global Business, Kogan Page Ltd., London, 2002.

Sullivan, Stefan. Marx For A Post-Communist Era on Poverty, Corruption, And Banality, Routledge, London, 2002.

The 2018 Corruption Perceptions Index, published by Transparency International. 